\title{
Optimal Design and Placement of Piezoelectric Actuators using Genetic Algorithm: Application to Switched Reluctance Machine Noise Reduction
}

\author{
Ojeda Javier ${ }^{1,3}$, Mininger Xavier², Gabsi Mohamed ${ }^{1}$ and Li Yongdong ${ }^{3}$

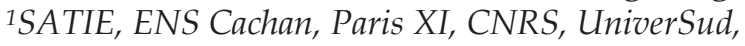 \\ 61, av President Wilson, F-94230 Cachan, \\ ${ }^{2}$ LGEP, CNRS UMR 8507; SUPELEC; UPMC Univ Paris 06; Univ Paris-Sud; \\ 11 rue Joliot-Curie, Plateau de Moulon, F-91192 Gif-sur-Yvette Cedex, \\ ${ }^{3} I P E M C$, Dept. Electrical Engineering, Tsinghua University, 100084 Beijing, \\ 1,2France \\ ${ }^{3}$ China
}

\section{Introduction}

Thanks to a good robustness, an easy production and high performances, switched reluctance machine (SRM) is an interesting drive for electro vehicular applications (Rahman et al., 2000) (Wang et al., 2005) or high speed applications (Kub et al., 2007). However, noise and vibrations generated by the SRM limit its integration. Previous studies on vibration reduction have considered SRM supplied by a pulsed current source. In this context, many solutions have been successfully applied to this problem such as adapted control schemes (Hong, 2002) and optimized stator design (Blaabjerg et al., 1994). However, these methods are less efficient in high speed operation zones. This chapter deals with the optimal placement and design of piezoelectric actuators used to reduce the noise and vibration generated by a SRM. Piezoelectric actuators are stuck on the SRM stator and controlled in order to reduce the generated vibrations. The design and placement are achieved by a genetic algorithm, NSGA II (Deb et al, 2002), with multi contradictory objectives in order to obtain a set of optimal solutions. Considering the number of actuators and the minimization of final displacement energy as contradictory objectives, a set of optima is found and a solution is chosen in order to be experimentally tested on a SRM.

In electrical machines, noise and vibrations are mainly due to aerodynamic (Fiedler et al., 2005), mechanical and magnetic issues. Aerodynamic vibrations are due to air displacement along rotating rotor (laminar flow) and vortices (turbulent flow) on SRM air gaps. These vibrations are located on inner surface of SRM stator. Mechanical vibrations are generated by relative movement between machine part and shock inside ball bearing. These vibrations are un-located on SRM. At last, magnetic vibrations are due to permeability gradient and generated on stator air-gap interface. Such sources can excite mechanical resonances of the structure and then generate vibratory displacement on the structure. Each source of noise 
contributes to the measured vibratory displacement with two different ways. On the one hand, forces generated by one part of sources such as magnetic forces or rotating flow on the SRM excite the mechanical behavior by a deterministic excitation depending on the rotational speed. On the other hand, these sources excite the mechanical behavior by a random excitation, like shocks inside ball bearing or the turbulent flow. In both cases, the vibratory displacement can be described by modal superposition theory as follow (Mininger et al., 2007), figure 1:

$$
d^{\text {ext }}(t, \theta)=\sum_{i \text { modes }}\left\{D_{i}^{\text {aero }}+D_{i}^{\text {mec }}+D_{i}^{\text {mag }}\right\} \cos i \theta \cos \omega_{i} t
$$

where dext is the measured vibratory displacement, $\theta$ the angular position of measurement on SRM stator, $i$ the considered vibration mode, $\omega_{i}$ the resonance frequency associated with the mode $i$ and $D^{x_{i}}$ the amplitude of excitation sources for each mode $i$.

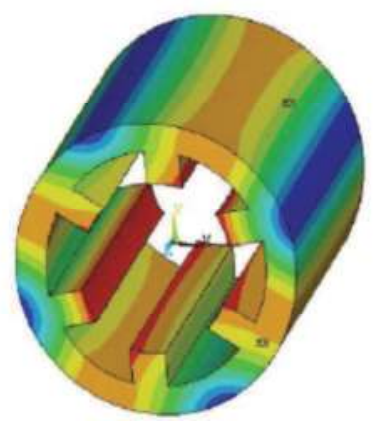

Fig. 1. Mode 2 resonance of SRM

This chapter is organized as follows: The first part deals with the optimization of dimensions and placement of piezoelectric actuators in the aim of reducing the generated vibrations. In this paragraph, the purpose and formulation used for the stochastic optimization is detailed. The second part deals with the validation of the optimization results by the mean of finite element simulations and experimental tests on a switched reluctance machine with piezoelectric actuators.

\section{Optimal design and placement by genetic algorithm}

\subsection{Purpose of the optimization}

The non dominated sorting genetic algorithm (NSGA-II) is an efficient multiobjective evolutionary algorithm based on both genetic laws and Darwin evolution (Deb and al, 2002). From an initial population composed of individuals and with crossover, mutation, and selection sequences for these individuals, a final optimal population is created. This final population constitutes a set of optimal solutions of the initial problem that respect the constraints and minimize objectives. NSGA-II algorithm includes the selection of individuals in the objective functions. In order to determine this function, one approach is suggested. This approach, based on final displacement minimization, corresponds to an electrical engineering approach and takes into account modeling both the electrical feed and the rotational speed. 
Genetic algorithm, NSGA-II, has been efficiently applied on other applications (Besnerais et al., 2007) (Qiu et al, 2007) due to its performances and its implementation on non linear problems. From a random initial population corresponding to a set of configurations (placement and design), an optimal set of solutions is found by best individual selections, crossovers and mutations. The main topic of this chapter is the design and placement of PZT actuators in order to reduce the SRM vibrations and, consequently, the level of noise generated. These design and placement steps are performed in the presence of constraints (no overlap of actuators, maximum actuator number) and opposite objectives: minimizing the number of actuators, while maximizing vibration damping. Thus, not only one single optimal solution exists, but also a set of optimal solutions (Pareto front). The simulation scheme is given in figure 2 .

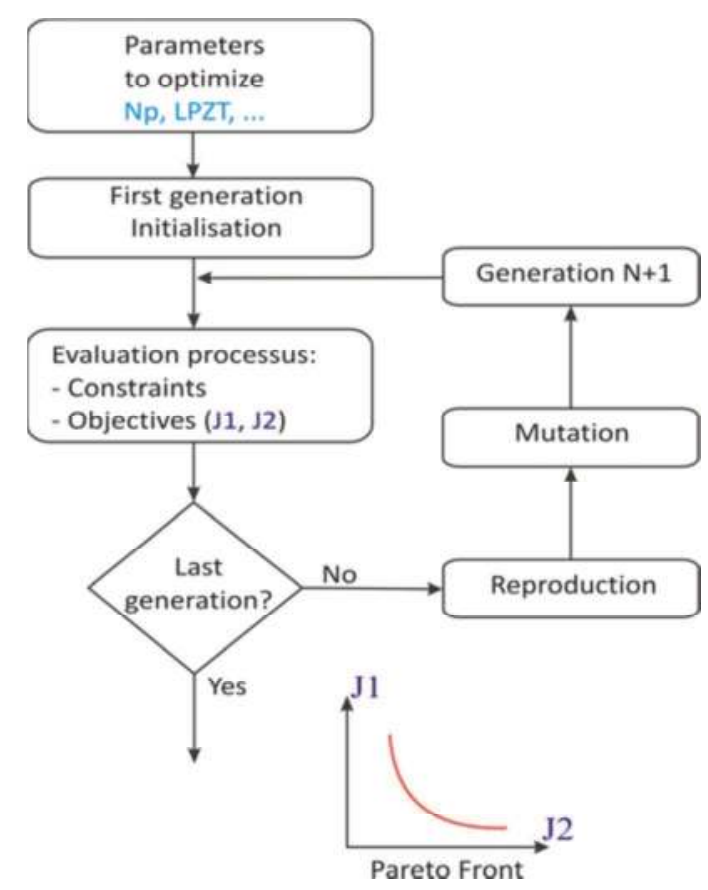

Fig. 2. NSGA II optimization scheme (Np: Number of actuators, Lpzt: length of an actuator)

Under these conditions, a genetic algorithm is more suitable than a determinist one.

\subsection{Optimization formulation for active damping}

Optimization is achieved with two opposite objectives used for individual selection: the number of PZT actuators $\left(J_{1}\right)$ and the resulting RMS global displacement $\left(J_{2}\right)$ after active damping. The minimization of the two objectives $J_{1}$ and $J_{2}$ allows the selection of the actuators optimal configuration.

$$
J_{2}=\sum_{i \text { modes }} \frac{\omega_{\mathrm{i}}^{2}}{4 \pi^{2}} \int_{0}^{2 \pi} \int_{0}^{2 \pi / \omega_{\mathrm{i}}}\left\{d_{i}^{\text {ext }}(\mathrm{t}, \theta)+\sum_{\text {actuators }} d_{i}^{P Z T}(\mathrm{t}, \theta)\right\}^{2} \mathrm{~d} \theta \mathrm{dt}
$$


$d_{i}$ ext is the modal displacement due to disturbance external forces (aerodynamic, mechanical and magnetic) on the SRM stator for a vibration mode i. $d_{i} P Z T$ is the controlled modal displacement due to designed and placed PZT actuators for a mode $i$. According to linear modeling of piezoelectric actuators, the vibratory displacement generated is expressed with the expression (1) (Young et al., 2003):

$$
d_{i}^{P Z T}(\mathrm{t}, \theta)=\sum_{i \text { modes }}\left\{\mathrm{K}_{\mathrm{i}}^{\mathrm{PZT}} \mathrm{V}_{\mathrm{i}}^{\mathrm{PZT}}\right\} \cos i\left(\theta-\theta_{i}\right) \cos \left(\omega_{i} t-\varphi_{i}\right)
$$

$\mathrm{K}_{\mathrm{i}} \mathrm{PZT}$ is the PZT conversion coefficient which depends on the geometry and material properties (Young's modulus, piezoelectric coefficient $\mathrm{d}_{31} \ldots$ ) for the considered mode. $\mathrm{V}_{\mathrm{i}} \mathrm{PZT}$ is the voltage applied to the piezoelectric actuator for the considered mode. $\theta_{\mathrm{i}}$ and $\varphi_{\mathrm{i}}$ are mechanical angle (angular placement of the actuator) and the electrical phase applied to the actuator for the considered mode, respectively.

Each individual is composed by the number of actuators and corresponding dimensions (length, thickness and angular position). The associated population size (1000 individuals) and the number of generation (1000 generations) are designed in order to have good constitution heterogeneity of individuals and enough iterations for convergence. The optimization result is a set of best individuals minimizing the two objectives and represented by a Pareto front.

The minimization problem is realized with constraints. First, overlap between two actuators is not allowed (same angular position) and second, geometrical parameters (actuators thickness, length and height) have limited range. The experimental actuator control is realized by a Matlab Simulink platform. Thus, the actuator voltage is also limited to $\pm 10 \mathrm{~V}$. Figure 3 represents the Pareto front of optima individuals according to selection functions $J_{1}$ and $J_{2}$ considering 4 modes: mode 2 at $5000 \mathrm{~Hz}$, mode 3 at $12600 \mathrm{~Hz}$, mode 4 at $21400 \mathrm{~Hz}$ and mode 5 at $29700 \mathrm{~Hz}$.

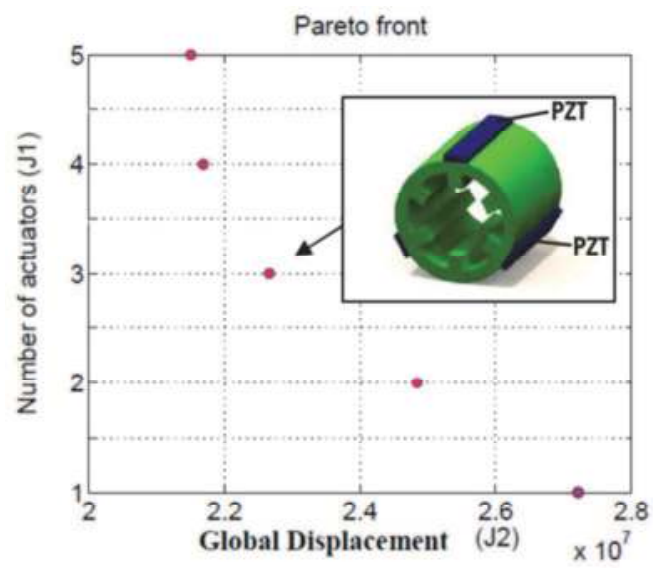

Fig. 3. Pareto configuration optima for actuator placement with an example of optimal individuals

After optimization, all dimensions for each configuration of actuators are the same: length, $40 \mathrm{~mm}$; thickness, $2.4 \mathrm{~mm}$; height, $12 \mathrm{~mm}$ and correspond to analytical optima. As the 
optimum placement, for the control of mode 2, does not correspond to optimum placement considering the other modes, thus, the angular placement is a compromise between the damping of each mode. It is the main reason to use the genetic algorithm (compared to determinist algorithm) because many optima exist. Considering one actuator the best placement is obtained on modes anti-nodes. However, only few positions correspond to antinodes for several modes. Thus, in the Pareto front the number of actuators increasing from one to two actuators decreases strongly the vibratory displacement reduction. However, when the number of actuators increases from four to five actuators, the displacement energy decreasing is less efficient. The final decision for one configuration of actuators depends on designer criterions, as the price or the manufacturing ease. In our application, the optimal solution with 3 actuators has been chosen. In order to keep the $180^{\circ}$ symmetry of the structure, 3 more actuators have been placed at $180^{\circ}$ with the same dimension of the others. The final SRM with PZT actuators is represented on the following figure 4.

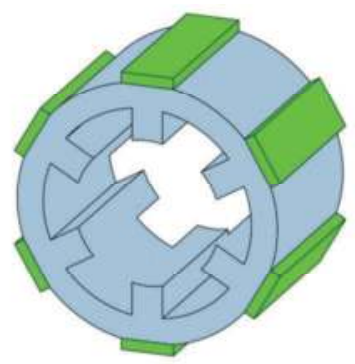

Fig. 4. Final design and placement of PZT actuators

\section{Finite element and experimental validation}

\subsection{Finite element active damping results}

For this configuration of actuators, finite element simulations allow the validation of the placement and the design of piezoelectric actuators for several vibration excitations. Forces exciting one or multiple modes are imposed on the stator and adequate voltages are applied to the actuators in order to reduce the resulting vibratory acceleration. Different voltage amplitudes are tested so as to conclude on the efficiency of this active damping method.

On Figure 5, a sinusoidal force corresponding to the mode 2 resonance of stator is applied on stator teeth. For the first phase, the associated vibratory displacement can be described by:

$$
d_{2}^{\text {ext }}(\mathrm{t}, \theta) \propto \cos 2 \theta \cos \omega_{\text {mode } 2} t
$$

Displacements associated with the two phases are deduced from the first phase applying a mechanical and electrical phase of $\pm 120^{\circ}$. These forces generate a vibratory displacement on the stator (curve $\mathrm{V}_{\mathrm{PZT}}=0 \mathrm{~V}$ ). Voltages, which temporal phases opposite to the ones of the forces on the teeth, are applied on PZT actuators $\left(\mathrm{V}_{\mathrm{PZT}}=5 \mathrm{~V}\right.$ and $\left.\mathrm{V}_{\mathrm{PZT}}=10 \mathrm{~V}\right)$. The electrical phase between two pairs of actuators is equal to $120^{\circ}$. For the first pair of actuators, the vibratory displacement generated is:

$$
d_{2}^{P Z T}(\mathrm{t}, \theta) \propto \mathrm{V}_{2}^{\mathrm{PZT}} \cos 2 \theta \cos \left(\omega_{\text {mode } 2} t-\varphi_{i}\right)
$$




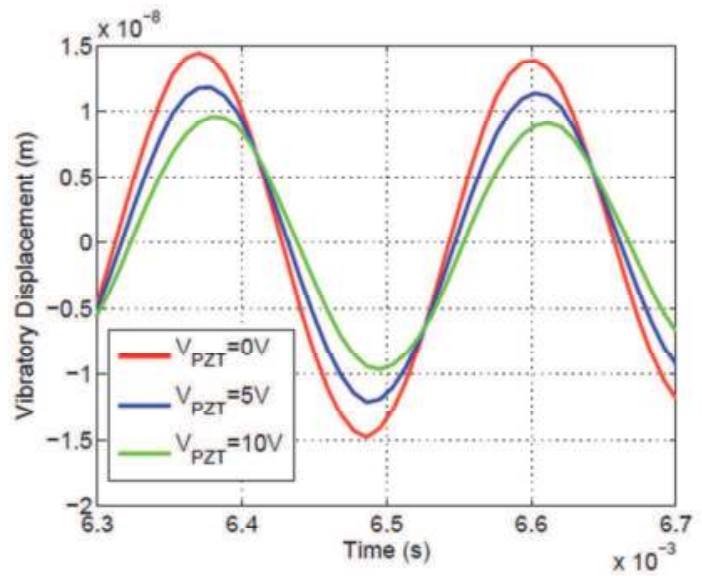

Fig. 5. Mode 2 active damping on SRM stator $(4.6 \mathrm{KHz})$

The vibratory displacement is reduced due to actuator interactions on structure (Mininger et al., 2007). The more the PZT voltage is increased, the more the vibratory displacement is reduced until the vibratory displacement is cancelled. In order to validate the superposition hypothesis, a multimodal configuration is considered. Figure 6 presents two sinusoidal forces corresponding to mode 2 and mode 4 resonances, which are applied on stator teeth of each phase:

$$
d_{2,4}^{\text {extPZT }}(\mathrm{t}, \theta) \propto \mathrm{A} \cos 2 \theta \cos \omega_{\text {mode } 2} t+\mathrm{B} \cos 4 \theta \cos \omega_{\text {mode } 4} t
$$

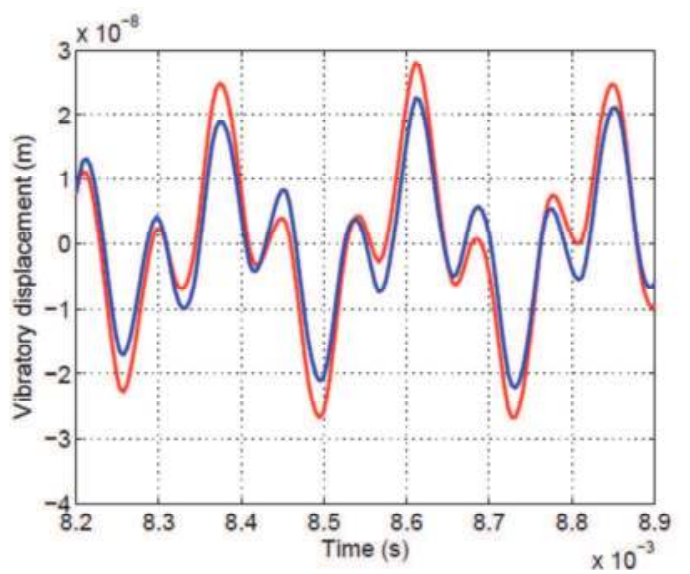

Fig. 6. Mode 2 and Mode 4 active damping on SRM stator (red: open loop, blue: closed loop)

Figure 7 is a Fast Fourier Transformation of the previous result. Without PZT voltage, the spectrum is composed by two excitations corresponding to mode 2 and mode 4 . With a mode 2 excitation of PZT actuators, only the mode 2 resonance is reduced. Thus, each mode can be treated separately. It is the starting point so as to design a controller for active damping so as to separately control the different modes. 


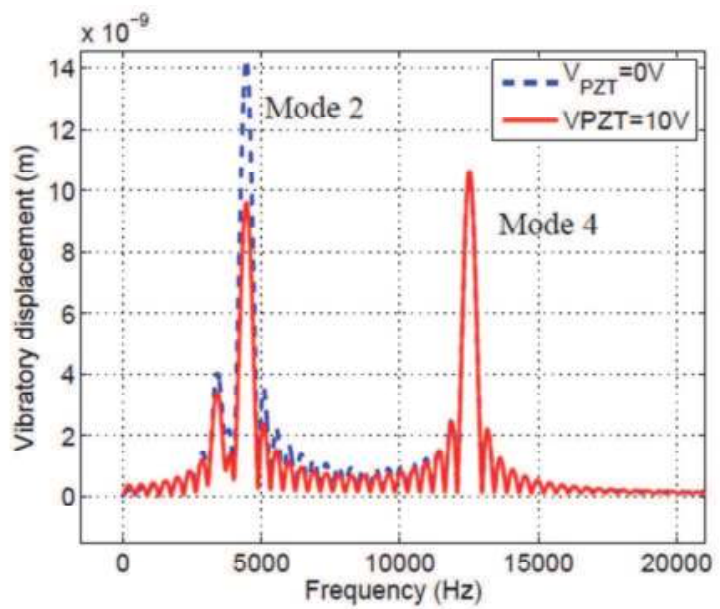

Fig. 7. Vibratory displacement FFT

\subsection{Experimental results with MIMO controller}

The experimental test bench, figure 8 , is composed by two motors sharing the same shaft: a Permanent Magnet (PM) one and the SRM. Using the PM motor, it is possible to obtain the rotation of the SRM without magnetic excitation of this one. In this case, only mechanical and aerodynamic disturbances are considered. The frame has been designed in order to minimize the vibration exchange between the two motors. Holes and slops on the frame are equivalent to multiple springs and are use to filter the vibration between the two motors.

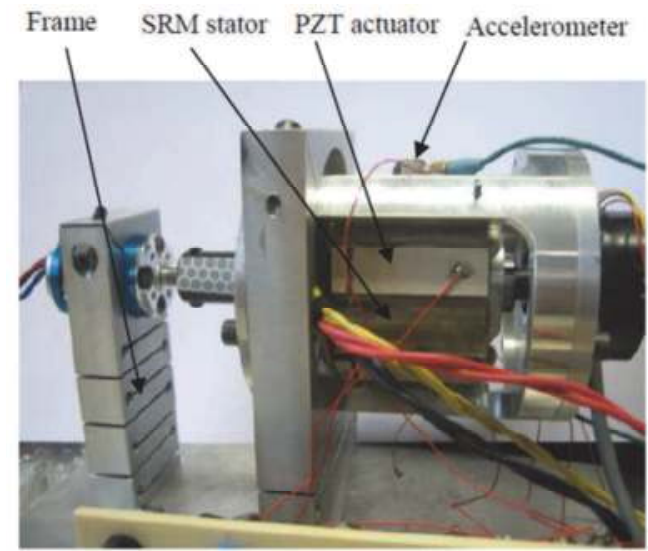

Fig. 8. Experimental test bench (left motor: PM motor, right motor: SRM)

The PZT voltage control is a multi-input multi-output system, figure 9.

On figure 9, the inputs of the control system are the vibratory displacements deduced from the vibratory acceleration measured on two stator points. The system outputs are the 3 PZT voltages applied to PZT phase 1, 2 and 3. Each PZT phase is composed by two PZT actuators controlled by the same voltage. 


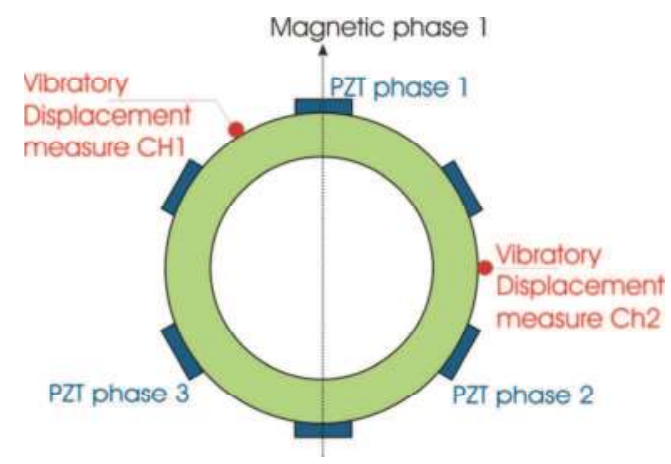

Fig. 9. Scheme representation of actuators and sensors placement

Considering only the piezoelectric excitation, the vibratory measurements in $\mathrm{CH} 1$ and $\mathrm{CH} 2$ depend on the voltage applied to the PZT phase 1, 2 and 3. In this case, the mode 2 vibratory displacement measurements in $\mathrm{CH} 1$ and $\mathrm{CH} 2$ can be expressed by:

$$
\left(\begin{array}{l}
d_{2}^{C H 1} \\
d_{2}^{C H 2}
\end{array}\right)=\left(\begin{array}{lll}
0.5 & 0.5 & -1 \\
-1 & 0.5 & 0.5
\end{array}\right)\left(\begin{array}{l}
d_{2}^{P Z T, 1} \\
d_{2}^{P Z T, 2} \\
d_{2}^{P Z T, 3}
\end{array}\right)
$$

One can see that one pair of actuators is more efficient than the two others to act on the displacement associated to one $\mathrm{d}_{2} \mathrm{CH}$ (e.g. PZT 3 for $\mathrm{d}_{2} \mathrm{CH} 1$ ). Indeed, it is placed on the corresponding antinode for mode 2 , the controller is then realized so as to un-correlate each PZT with each measurement point and on the same time maximizes the influence of the measured vibratory displacement to the corresponding PZT phase.

Often used on active damping problem and resonant system, the Positive Position Feedback (PPF), is an efficient controller for one input one output system (Preumont, 2002). The controller described in this paper is based on three PPF controllers (Moheimani et al., 2005), and each PPF controller controls only one PZT phase. The uncoupling between each phase (e.g. PZT 3 acting only on $\mathrm{d}_{2} \mathrm{CH}$ ) on measurement points is realized by a matrix gain $(\mathrm{G})$.

$$
(G)=\left(\begin{array}{ccc}
1 & -0.5 & -0.5 \\
-0.5 & 1 & -0.5 \\
-0.5 & -0.5 & 1
\end{array}\right)
$$

Assuming, a third virtual measurement point $\mathrm{CH} 3$ exists defined by the relation $\mathrm{d}_{2} \mathrm{CH} 1+\mathrm{d}_{2}$ $\mathrm{CH} 2+\mathrm{d}_{2} \mathrm{CH} 3=0$, the system can be defined by:

$$
\left(\begin{array}{l}
V_{2}^{P Z T, 1} \\
V_{2}^{P Z T, 2} \\
V_{2}^{P Z T, 3}
\end{array}\right)=\left(\begin{array}{ccc}
H_{P P F}(s) & 0 & 0 \\
0 & H_{P P F}(s) & 0 \\
0 & 0 & H_{P P F}(s)
\end{array}\right)(G)\left(\begin{array}{l}
d_{2}^{C H 1} \\
d_{2}^{C H 2} \\
d_{2}^{C H 3}
\end{array}\right)
$$

The filter $\mathrm{H}_{\mathrm{PPF}}(\mathrm{s})$ is design by Mac Ever method (McEver, 1999) and is defined as:

$$
H_{P P F}(s)=\frac{H_{O}}{1+2 m_{P P F} \frac{s}{\omega_{P P F}}+\frac{s^{2}}{\omega_{P P F}^{2}}}
$$


The PPF filter has an only significant action on vibratory problem around a central frequency, increasing the equivalent damping ratio around this frequency. Thus, it has been designed in order to reduce the vibratory acceleration, and consequently the vibratory displacement, around the mode 2 resonance frequency $(5000 \mathrm{~Hz})$. The controller scheme is given in figure 10 .

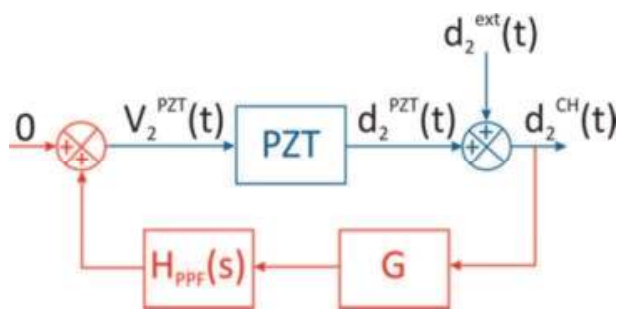

Fig. 10. PPF controller scheme for active damping

So as to test the active damping robustness, an experimental test has been realized on the more disadvantageous case. In this case, the vibration generated on the SRM stator is generated by aerodynamic and mechanical excitations. On figure 11, the active damping has been tested at $10000 \mathrm{rpm}$.
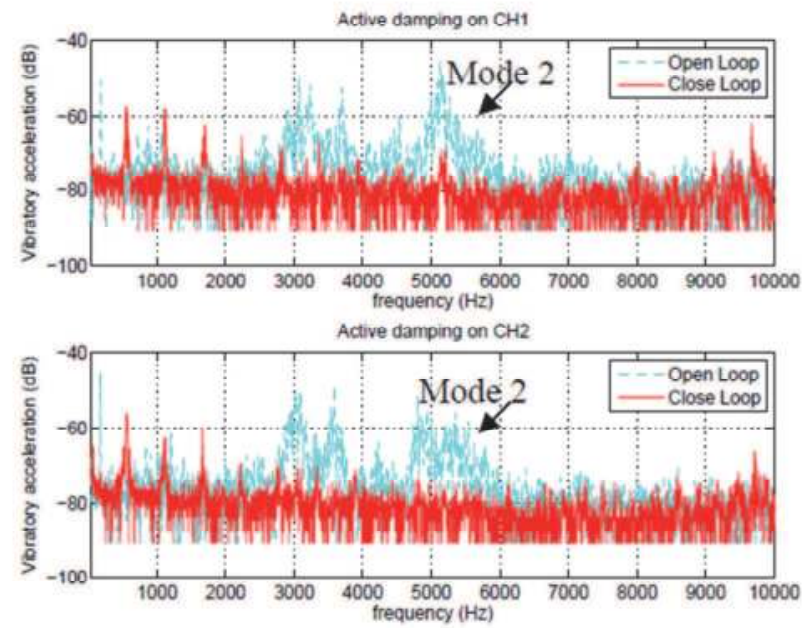

Fig. 11. Experimental active damping at $10000 \mathrm{rpm}$

A significant reduction of the vibratory acceleration has been measured. With this principle, a vibratory reduction from $15 \mathrm{~dB}$ is obtained around the PPF filter frequency from a large range of rotational speed from $1 \mathrm{rpm}$ to $15000 \mathrm{rpm}$. This method is efficient on both low and high speed operation range. Moreover, the method has been successfully applied with all kind of excitations (Ojeda et al., 2007).

\section{Conclusion}

In this chapter, design and placement of piezoelectric actuators by genetic algorithm have been presented in the aim of SRM noise damping. A formulation based on the vibratory 
displacement energy reduction has been successfully applied so as to select optimal configuration of actuators. Piezoelectric actuators have been used in order to reduce the noise generated by SRM functioning in a large operation range. Optimal placement and design allow the reduction of all vibration sources by the actuator voltage control. This compensation method with optimized design and placement allows a $15 \mathrm{~dB}$ noise reduction in audible frequencies. It could be efficiently applied on all low vibration applications using electrical machines, like compressors or flight direction.

\section{References}

Besnerais, J. L.; Hequet, M.; Lanfranchi, V. \& Brochet, P. Multi-objectives optimization of the induction machine with minimization of audible electromagnetic noise, European Physical Journal, 2007.

Blaabjerg, F.; Pedersen, J.; P. Nielsen, Andersen, L. \& Kjaer P. Investigation and reduction of acoustical noise from switched reluctance drives in current and voltage control, in Proc. 1994 International Conference on Electrical Machines, pp. 589-594, 1994.

Deb, K.; Amrit, P.; Sameer, A. \& Meyarivan T. A fast and elitist multi- objective genetic algorithm: NSGA-II, IEEE Trans. Evol. Comput., vol. 6, no. 2, pp. 182-197, Apr. 2002.

Fiedler, J.O.; Kasper, K. A. \& De Doncker, R. W. Acoustic noise in switched reluctance drives: an aerodynamic problem?, IEEE IEMDC conference, 2005.

Hong, J. Stator pole and Yoke design for vibration reduction of switched reluctance motor, IEEE Transactions on Magnetics, 38(2):929-932, Mars 2002.

Kub, H.; Wichert, BT. \& Szymanski, B. Design of a high speed switched reluctance motor for spindle drive, Compatibility in power electronics, CPED'07, pp. 1-5, 2007

Rahman, K. M.; Fahimi, R.; Suresh, G.; Rajarathnam, A. V. \& Ehsani, M. Advantages of switched reluctances motor, applications to EV and HEV: Design and control issues, IEEE transactions on industry applications, Vol.36 N.1, 2000.

Mininger, X.; Gabsi, M.; Lécrivain, M.; Lefeuvre, E.; Richard, C.; Guyomar, D. \& Bouillault, F. Vibration damping with piezoelectric actuators for electrical motors, COMPEL, Vol. 26, N.1, 2007.

Moheimani, SOR.; Vautier, BJG. \& Bhikkaji, B. Experimental implementation of extended multivariable PPF control on an active structure, Control Systems Technology, IEEE Transactions on, Vol. 14, pp. 443-45, 2006.

Preumont, A. Vibration control of active structures an introduction, 2nd ed., Kluwer academic publishers, 2002.

McEver, M. Optimal vibration suppression using on-line pole/zero identification, $P H D$ Thesis, Faculty of Virginia Polytechnic Institute and State University, 1999.

Ojeda, X.; Mininger, X.; Gabsi M. \& Lécrivain, M. Noise reduction using piezoelectric active control on high speeds switched reluctance drives, IAS conference, 2007.

Qiu, Z.; Zhang, X.; Wu, H. \& Zhang H. Optimal placement and active vibration control for piezoelectric smart flexible cantilever plate, Journal of sound and Vibration, Vol. 301, pp. 521-543, 2007

Wang, S.; Zhan, Q.; Ma, Z. \& Zhou, L. Implementation of a 50-kW four-phase switched reluctance motor drive system for hybrid electric vehicle, Magnetics, IEEE transactions on, Vol. 41, pp. 501-504, 2005.

Young, WC.; Budynas RG. \& Roark RJ. Roark's formulas for stress and strain, Tsinghua University Press, 2003 


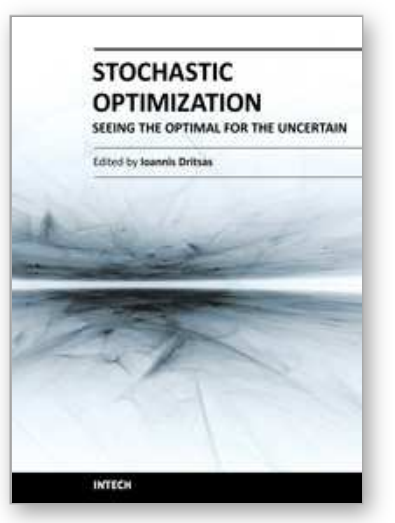

\author{
Stochastic Optimization - Seeing the Optimal for the Uncertain \\ Edited by Dr. loannis Dritsas
}

ISBN 978-953-307-829-8

Hard cover, 476 pages

Publisher InTech

Published online 28, February, 2011

Published in print edition February, 2011

Stochastic Optimization Algorithms have become essential tools in solving a wide range of difficult and critical optimization problems. Such methods are able to find the optimum solution of a problem with uncertain elements or to algorithmically incorporate uncertainty to solve a deterministic problem. They even succeed in â€œfighting uncertainty with uncertaintyâ€. This book discusses theoretical aspects of many such algorithms and covers their application in various scientific fields.

\title{
How to reference
}

In order to correctly reference this scholarly work, feel free to copy and paste the following:

Ojeda Javier, Mininger Xavier, Gabsi Mohamed and Li Yongdong (2011). Optimal Design and Placement of Piezoelectric Actuators using Genetic Algorithm: Application to Switched Reluctance Machine Noise Reduction, Stochastic Optimization - Seeing the Optimal for the Uncertain, Dr. loannis Dritsas (Ed.), ISBN: 978-953-307829-8, InTech, Available from: http://www.intechopen.com/books/stochastic-optimization-seeing-the-optimalfor-the-uncertain/optimal-design-and-placement-of-piezoelectric-actuators-using-genetic-algorithm-applicationto-switc

\section{INTECH}

open science | open minds

\section{InTech Europe}

University Campus STeP Ri

Slavka Krautzeka 83/A

51000 Rijeka, Croatia

Phone: +385 (51) 770447

Fax: +385 (51) 686166

www.intechopen.com

\section{InTech China}

Unit 405, Office Block, Hotel Equatorial Shanghai

No.65, Yan An Road (West), Shanghai, 200040, China

中国上海市延安西路65号上海国际贵都大饭店办公楼 405 单元

Phone: $+86-21-62489820$

Fax: $+86-21-62489821$ 
(C) 2011 The Author(s). Licensee IntechOpen. This chapter is distributed under the terms of the Creative Commons Attribution-NonCommercialShareAlike-3.0 License, which permits use, distribution and reproduction for non-commercial purposes, provided the original is properly cited and derivative works building on this content are distributed under the same license. 